\title{
Reduction of diagnostic and treatment delays reduces rifampicin-resistant tuberculosis mortality in Rwanda
}

\author{
J-C. S. Ngabonziza, 1,2,3 Y. M. Habimana, ${ }^{4}$ T. Decroo, ${ }^{5,6}$ P. Migambi, ${ }^{4}$ A. Dushime, ${ }^{4}$ J. B. Mazarati, ${ }^{7}$ \\ L. Rigouts, ${ }^{2,3}$ D. Affolabi, ${ }^{8}$ E. Ivan, ${ }^{1}$ C. J. Meehan, ${ }^{2,9}$ A. Van Deun, ${ }^{2,10}$ K. Fissette, ${ }^{2}$ I. Habiyambere, ${ }^{4}$ \\ A. U. Nyaruhirira, ${ }^{11}$ I. Turate, ${ }^{12}$ J. M. Semahore, ${ }^{13}$ N. Ndjeka, ${ }^{14}$ C. M. Muvunyi, ${ }^{15}$ J. U. Condo, ${ }^{16}$ \\ M. Gasana, ${ }^{4}$ E. Hasker, ${ }^{17}$ G. Torrea, ${ }^{2}$ B. C. de Jong ${ }^{2}$ \\ ${ }^{1}$ National Reference Laboratory Division, Department of Biomedical Services, Rwanda Biomedical Centre, Kigali, \\ Rwanda; ${ }^{2}$ Mycobacteriology Unit, Department of Biomedical Sciences, Institute of Tropical Medicine, Antwerp, \\ ${ }^{3}$ Department of Biomedical Sciences, University of Antwerp, Antwerp, Belgium; ${ }^{4}$ Tuberculosis and Other \\ Respiratory Diseases Division, Institute of HIVIAIDS Disease Prevention and Control, Rwanda Biomedical Centre, \\ Kigali, Rwanda; ${ }^{5}$ Department of Clinical Sciences, Institute of Tropical Medicine, Antwerp, Belgium; ${ }^{6}$ Research \\ Foundation Flanders, Brussels, Belgium; ${ }^{7}$ Department of Biomedical Services, Rwanda Biomedical Centre, Kigali, \\ Rwanda; ${ }^{8}$ Laboratoire de Référence des Mycobactéries, Cotonou, Benin; ${ }^{9}$ School of Chemistry and Biosciences, \\ University of Bradford, Bradford, UK; ${ }^{10}$ International Union Against Tuberculosis and Lung Disease, Paris, France; \\ ${ }^{11}$ Management Sciences for Health, Pretoria, South Africa; ${ }^{12}$ Institute of HIV/AIDS Disease Prevention and Control, \\ Rwanda Biomedical Centre, Kigali, ${ }^{13} \mathrm{HIV}$, STIs, Hepatitis and Tuberculosis Programmes, World Health Organization \\ Country Office, Kigali, Rwanda; ${ }^{14}$ National Tuberculosis Programme, National Department of Health, Pretoria, \\ South Africa; ${ }^{15}$ Department of Clinical Biology, School of Medicine and Pharmacy, College of Medicine and Health \\ Sciences, University of Rwanda, Kigali; ${ }^{16}$ Rwanda Biomedical Centre, Kigali, Rwanda; ${ }^{17}$ Department of Public \\ Health, Institute of Tropical Medicine, Antwerp, Belgium
}

S U M M A R Y

SETTING: In 2005, in response to the increasing prevalence of rifampicin-resistant tuberculosis (RRTB) and poor treatment outcomes, Rwanda initiated the programmatic management of RR-TB, including expanded access to systematic rifampicin drug susceptibility testing (DST) and standardised treatment.

OBJECTIVE: To describe trends in diagnostic and treatment delays and estimate their effect on RR-TB mortality.

DESIGN : Retrospective analysis of individual-level data including $748(85.4 \%)$ of 876 patients diagnosed with RR-TB notified to the World Health Organization between 1 July 2005 and 31 December 2016 in Rwanda. Logistic regression was used to estimate the effect of diagnostic and therapeutic delays on RR-TB mortality.

RESULTS: Between 2006 and 2016, the median diag- nostic delay significantly decreased from 88 days to 1 day, and the therapeutic delay from 76 days to 3 days. Simultaneously, RR-TB mortality significantly decreased from $30.8 \%$ in 2006 to $6.9 \%$ in 2016 . Total delay in starting multidrug-resistant TB (MDR-TB) treatment of more than 100 days was associated with more than two-fold higher odds for dying. When delays were long, empirical RR-TB treatment initiation was associated with a lower mortality.

CONCLUSION: The reduction of diagnostic and treatment delays reduced RR-TB mortality. We anticipate that universal testing for RR-TB, short diagnostic and therapeutic delays and effective standardised MDR-TB treatment will further decrease RR-TB mortality in Rwanda.

KEY WORDS: TB; Rwanda; MDR-TB programmatic management; MDR-TB diagnosis; MDR-TB treatment
RIFAMPICIN (RMP) is the most powerful antituberculosis drug, and resistance to RMP is a reliable surrogate marker for multidrug-resistant tuberculosis (MDR-TB), a major challenge for TB management and control. ${ }^{1}$ Rapid diagnostic tools, such as Xpert ${ }^{\circledR}$ MTB/RIF (Cepheid, Sunnyvale, CA, USA), have greatly increased access to RMP drug susceptibility testing (DST) and reduced diagnostic delay. ${ }^{2}$

Globally, the vast majority $(75 \%)$ of new RMPresistant TB (RR-TB) patients remained undiagnosed in $2017,{ }^{3}$ fuelling RR-TB transmission. ${ }^{4}$ Logistical challenges related to sample transport and result reporting can cause diagnostic delays. ${ }^{5}$ Other challenges, such as the lack of decentralised RR-TB treatment or access to RR-TB drugs, can cause therapeutic delays in those already diagnosed. In 2017, the global RR-TB treatment success rate was a mere $55 \%,{ }^{3}$ with diagnostic and/or therapeutic delays associated with poorer treatment outcome and pre-treatment loss to follow-up (LTFU). ${ }^{2,6-13}$

Correspondence to: Jean-Claude Semuto Ngabonziza, Rwanda Biomedical Center, National Reference Laboratory Division, KN4AV, Kigali 7162, Rwanda. e-mail: jclaude.ngabonziza@rbc.gov.rw

Article submitted 1 May 2019. Final version accepted 26 August 2019. 
Table 1 Timeline showing changes to the programmatic management of MDR-TB in Rwanda

\begin{tabular}{|c|c|c|}
\hline Period/year & Intervention & Implementation context \\
\hline Before 2005 & Passive surveillance of drug-resistant TB & $\begin{array}{l}\text { Selected patients' samples (mostly those failing and relapsing from } \\
\text { the WHO Category } 2 \text { regimen) were shipped to collaborating } \\
\text { laboratory for DST, but no standard treatment for MDR/RR-TB }\end{array}$ \\
\hline 2005 & $\begin{array}{l}\text { Programmatic management of RR-TB and } \\
\text { systematic surveillance of drug-resistant TB } \\
\text { among retreated patients }\end{array}$ & $\begin{array}{l}\text { The programmatic management of RR-TB (PMDT) was launched as } \\
\text { a core component of the NTP.15 PMDT comprised countrywide } \\
\text { surveillance of drug-resistant TB among previously treated TB } \\
\text { patients and the standardised long-duration MDR-TB regimen. As } \\
\text { the NRL's capacity to perform DST was insufficient, patient } \\
\text { samples were shipped to external collaborating laboratories such } \\
\text { as the Institute of Tropical Medicine (Antwerp, Belgium), resulting } \\
\text { in long diagnostic delays }{ }^{26}\end{array}$ \\
\hline 2007 & $\begin{array}{l}\text { Strengthening RR-TB diagnostic capacity of the } \\
\quad \text { NRL }\end{array}$ & $\begin{array}{l}\text { The NRL introduced phenotypic DST using the proportion method } \\
\text { on Löwenstein-Jensen medium (phenotypic) }\end{array}$ \\
\hline 2009 & $\begin{array}{l}\text { Strengthening RR-TB diagnostic capacity of the } \\
\quad N R L\end{array}$ & $\begin{array}{l}\text { The NRL introduced GenoType }{ }^{\circledR} \text { MTBDRplus LPA (Hain Lifescience, } \\
\text { Nehren, Germany) for the rapid detection of MDR-TB }\end{array}$ \\
\hline 2012 & $\begin{array}{l}\text { Strengthening RR-TB diagnostic capacity at } \\
\text { referral laboratories }\end{array}$ & $\begin{array}{l}\text { Xpert }{ }^{\circledR} \text { MTB/RIF (Cepheid, Sunnyvale, CA, USA) was piloted in six } \\
\text { referral hospitals }\end{array}$ \\
\hline 2013 & $\begin{array}{l}\text { Strengthening RR-TB diagnostic capacity at the } \\
\text { countrywide laboratory network }\end{array}$ & $\begin{array}{l}\text { The logistics of sputum sample transportation ( } \geq 2 / \text { week motorbike } \\
\text { visits from each health centre to an Xpert site, and weekly sample } \\
\text { transportation from intermediate health facilities to connect with } \\
\text { LPA facilities) and timely reporting of results (phone call to a } \\
\text { dedicated NTP number in case of RR-TB results) strengthened this } \\
\text { diagnostic network. }{ }^{35} \text { Moreover, reducing the diagnostic delay } \\
\text { and a high number of Xpert tests was rewarded through a } \\
\text { performance-based financing policy }{ }^{29}\end{array}$ \\
\hline 2014 & Expending access to RR-TB rapid diagnostic & $\begin{array}{l}\text { Xpert testing was decentralised to the district hospital level and } \\
\text { became easily accessible to all } 515 \text { peripheral health facilities as } \\
\text { first-line diagnostics for all those aged } \geq 55 \text { years and presumptive } \\
\text { TB patients with HIV coinfection, as well as all smear-positive TB } \\
\text { patients. }{ }^{15} \text { The shorter MDR-TB treatment regimen was } \\
\text { introduced. }{ }^{36} \text { All patients diagnosed with RR-TB were considered } \\
\text { eligible for the shorter MDR-TB regimen (previously only those } \\
\text { patients diagnosed with rifampicin and isoniazid resistance, i.e., } \\
\text { MDR-TB, were eligible for the long regimen). Effective } \\
\text { coordination between diagnostic centres and the Rwandan health } \\
\text { facilities where TB care is provided was essential }\end{array}$ \\
\hline
\end{tabular}

MDR-TB = multidrug-resistant TB; TB = tuberculosis; $\mathrm{WHO}=$ World Health Organization; RR-TB = rifampicin-resistant TB; PMDT = programmatic management of drug resistant TB; NTP = National Tuberculosis Control Programme; DST = drug susceptibility testing; NRL= national reference laboratory; LPA = line-probe assay; $\mathrm{HIV}=$ human immunodeficiency virus.

However, evidence on the effect of shortened delays on RR-TB mortality is lacking. ${ }^{14}$

In Rwanda, the first patients with RR-TB were documented in 1989 at the Kigali University Hospital, Kigali, Rwanda. No standardised treatment regimen was available and little could be offered to these patients. ${ }^{15}$ In 2005, the programmatic management of RR-TB (PMDT) was launched as a core component of the National TB Control Programme (NTP). ${ }^{15}$ Countrywide access to RR-TB testing and MDR-TB treatment increased (Table 1). However, the effect of increased access and shortened delays on RR-TB mortality has never been investigated in Rwanda. We therefore studied data from all RR-TB patients since the start of PMDT in Rwanda-a study period of more than 10 years in order 1) to describe trends in RR-TB diagnosis and enrolment into MDR-TB treatment, 2) to compare diagnostic and therapeutic delays between different RMP DST methods and 3) to estimate the association between shortened delays and RR-TB mortality. To the best of our knowledge, this is the first such nationwide population-based study.

\section{METHODS}

\section{Design and study population}

In this longitudinal retrospective analysis, we included consecutive patients diagnosed with pulmonary RR-TB who were registered between July 2005, when the PMDT started, and December 2016.

\section{Data collection}

Patients were assigned a unique ID on treatment initiation, or laboratory ID for those who did not start treatment. Patient files were retrieved from their respective health facilities. The National MDR-TB register and the National Reference Laboratory (NRL) registers were reviewed to extract relevant data.

A standardised data collection tool (see Supplementary Data) was used to capture demographics, baseline clinical characteristics, type of RMP DST used for diagnosis, dates of sample collection for RMP DST, dates that RMP DST results were available at the RR-TB testing laboratory, date of MDR-TB treatment initiation, the programmatic 
outcome (death before treatment initiation, death during treatment, treatment success-cure or treatment completion, treatment failure, treatment discontinuation and LTFU) and the outcome date.

Two trained MDR-TB experienced nurses collected the data. They were supervised by the investigators. Data were double-entered in a dedicated EpiData database (EpiData Association, Odense, Denmark) by two encoders. Discordances were resolved by referring to the source.

\section{Definition of variables}

RR-TB diagnostic delay was defined as the number of days between the date of collection of the first sputum sample that led to RR-TB diagnosis and the date that RMP DST results became available at the laboratory. RR-TB therapeutic delay was defined as the number of days between the date that RMP DST results became available at the laboratory and the date that MDR-TB treatment was started. Total RR-TB delay was defined as the sum of RR-TB diagnostic delay and RR-TB therapeutic delay.

A binary outcome "mortality" was constructed. Patients were categorised as "dead" if they died before or during MDR-TB treatment or as "survived throughout treatment", after excluding those with treatment failure or LTFU. In a sensitivity analysis, patients with treatment failure or LTFU were considered as dead (worst case scenario). It is plausible that the majority of these patients with MDR-/RR-TB and without (sufficient) treatment died.

\section{Data analysis}

RR-TB incidence was calculated as an average of cases registered in three recent years $(2014,2015$ and 2016) divided by the estimated population size (2012 Demographic and Health Survey), and was expressed per 100000 population. The equality-of-medians test was used to compare the median delays within groups. RR-TB diagnostic delay and RR-TB therapeutic delay were categorised to facilitate logistic regression. Univariate analysis was conducted for each independent variable with mortality as the outcome variable. To assess the effect of both types of delay on mortality, adjusted for potential confounders, variables with $P<0.2$ on univariate analysis were included, together with both delay variables in the multivariable logistic regression analysis. Statistical significance was set at 0.05 . Kaplan-Meier techniques were used to estimate survival. Follow-up time started on the date of the first sputum sample collection that led to RR-TB diagnosis, the outcome event was death. Patients who survived throughout treatment were censored on the date of treatment outcome. STATA v14.2 (Stata Corp, College Station, TX, USA) was used for data analysis.
Table 2 RR-TB national notification vs. proportion sampled

\begin{tabular}{lcc}
\hline Year & $\begin{array}{c}\text { RR-TB notification } \\
n\end{array}$ & $\begin{array}{c}\text { Sampled for the study } \\
n(\%)\end{array}$ \\
\hline 2005 and 2006 & 90 & $67(74.4)$ \\
2007 & 102 & $94(92.2)$ \\
2008 & 74 & $73(98.6)$ \\
2009 & 80 & $80(100)$ \\
2010 & 91 & $86(94.5)$ \\
2011 & 82 & $66(80.5)$ \\
2012 & 57 & $53(93.0)$ \\
2013 & 43 & $41(95.3)$ \\
2014 & 82 & $73(89.0)$ \\
2015 & 94 & $77(81.9)$ \\
2016 & 81 & $77(95.1)$ \\
Total & 876 & $787(89.8)$ \\
\hline
\end{tabular}

RR-TB $=$ rifampicin-resistant tuberculosis

\section{Ethics}

The study protocol was approved by the Rwanda National Ethical committee (RNEC), Kigali, Rwanda (IRB 00001497 of IORG0001100; Ref No.0069/ RNEC/2017); the Institutional Review Board of the Institute of Tropical Medicine, Antwerp, Belgium (IRB/AB/AC/062; Ref No. 1208/17; 19/03/2018); and the Ethics Committee of the Antwerp University Hospital (UZA, Universitair Ziekenhuis Antwerpen Ethische Commissie), Antwerp, Belgium (REG No. B300201836458; 14/05/2018).

\section{RESULTS}

From 1 July 2005 to 31 December 2016, the Rwanda NTP notified 876 patients with RR-TB. Of these, 787 $(89.8 \%)$ had available records available (Table 2, Figure 1), 730 (92.7\%) of whom were included in the primary RR-TB mortality analysis, while 39 (5.0\%) were excluded from any analysis and 18 were only included in the sensitivity analysis.

Of the 730 eligible RR-TB patients, more were male $(57.5 \%)$ and the median age was 34 years (interquartile range [IQR] 27-43). The human immunodeficiency virus (HIV) co-infection status was documented for 698 (95.6\%), 291 (39.9\%) of whom were HIV co-infected (Table 2); this remained stable over the study period $(P=0.28$, data not shown). The majority of the patients $(n=390$, $53.7 \%$ ) came from Kigali City, with an estimated RRTB incidence of 2.38 per 100000 population per year, with the lowest incidence in Northern Province (0.21/ $100000)$.

Of the 730 RR-TB patients, $49(6.7 \%)$ died before starting treatment (Table 3). In 611/681 (89.7\%) patients, treatment initiation was based on the RMP DST result, while in 70 (10.3\%), MDR-TB treatment initiation was based on a presumptive RR-TB diagnosis, most of whom $(70 / 74,94.6 \%)$ were confirmed later. The majority $(n=510,74.9 \%)$ of the patients were treated with the World Health Organization (WHO) long regimen, and 171 (25.1\%) 


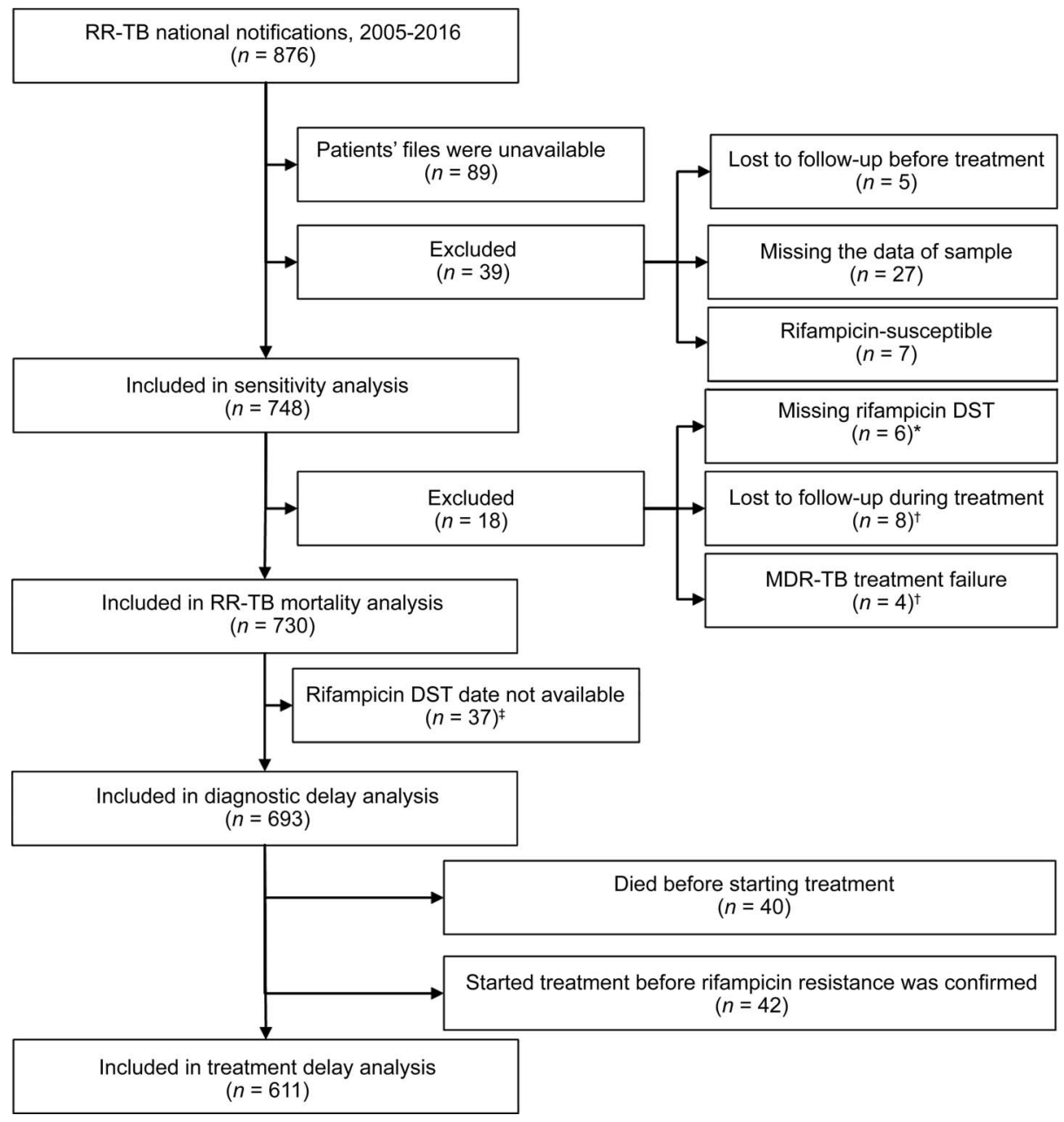

Figure 1 Flowchart showing inclusion and exclusion criteria for study participants. * Programmatic outcome used in sensitivity analysis. ${ }^{\dagger}$ In sensitivity analysis, we assumed the worst outcome (death) in these patients diagnosed with RR-TB, but without treatment or treatment failed. ${ }^{*}$ Includes patients who died before starting treatment $(n=9)$ and 28 patients who started treatment before RR-TB confirmation. RR-TB = rifampicin-resistant tuberculosis; DST = drug susceptibility test; MDR-TB $=$ multidrug-resistant TB.

were treated with the shorter regimen, ${ }^{16,17}$ which was introduced in mid-2014.

The history of TB treatment was known for 697 $(95.5 \%)$ patients: $511(73.3 \%)$ were previously treated for TB and $186(26.7 \%)$ were new TB patients, $149(80.1 \%)$ of whom had been diagnosed since 2013 . The ratio of new to previously treated TB was 1.5:1 since 2013, a sharp increase from 0.09:1 before 2013. Among previously treated TB patients, the majority $(n=215,79.6 \%)$ had failed the WHO Category 2 treatment regimen before 2010, while over half of patients $(124,51.5 \%)$ had failed Category 1 (Figure 2) since 2010.

Among the 611 patients initiated on treatment based on confirmed RR-TB, 228 (100\%) were initiated based on phenotypic DST before 2009, which decreased to $3(1.2 \%)$ after the implementation of line-probe assays (LPAs) and Xpert (Figure 3). After the countrywide scale-up of Xpert testing in 2014, $170(81.3 \%)$ patients were initiated based on
Xpert results and $39(18.7 \%)$ based on LPA results, and none based on phenotypic DST (Figure 3).

\section{$R R-T B$ diagnostic and treatment delays}

The date of RR-TB diagnosis was available for 693/ 730 patients, (Figure 1): the overall median diagnostic delay was 58 days (IQR 6-85). Of these 693 patients, 82 were excluded from the therapeutic delay analysis, as they died before starting treatment $(n=$ $40)$ or started treatment before RR-TB confirmation $(n=42)$ (Figure 1); the remaining 611 patients had an overall median therapeutic delay of 8 days (IQR 420).

The median diagnostic delay was significantly longer for patients diagnosed using phenotypic DST (median 87 days, IQR 78-98) compared to LPA (median 40 days, IQR 25-55) or Xpert (median 1 day, IQR 0-3) $(P<0.01)$. The median therapeutic delay was 2.6 times longer for patients who initiated treatment based on phenotypic DST (median 21 days, 
Table 3 Characteristics of RR-TB patients diagnosed between 2005 and 2016 in Rwanda, who were included in the analysis ( $n$ $=730$ )

\begin{tabular}{|c|c|}
\hline & $n(\%)$ \\
\hline $\begin{array}{l}\text { Sex } \\
\quad \text { Male } \\
\text { Female }\end{array}$ & $\begin{array}{l}420(57.5) \\
310(42.5)\end{array}$ \\
\hline $\begin{array}{l}\text { Age, years } \\
<30 \\
30-44 \\
45-54 \\
>54 \\
\text { Unknown } \\
\text { Median [IQR] }\end{array}$ & $\begin{array}{c}252(34.5) \\
307(42.1) \\
96(13.2) \\
71(9.7) \\
4(0.6) \\
34[27-43]\end{array}$ \\
\hline $\begin{array}{l}\text { Province } \\
\text { East } \\
\text { Kigali } \\
\text { North } \\
\text { South } \\
\text { West } \\
\text { Other country (Uganda) }\end{array}$ & $\begin{array}{c}85(11.6) \\
390(53.7) \\
36(4.9) \\
144(19.7) \\
72(9.9) \\
3(0.4)\end{array}$ \\
\hline $\begin{array}{l}\text { HIV status } \\
\text { Negative } \\
\text { Positive } \\
\text { Unknown }\end{array}$ & $\begin{array}{c}407(55.7) \\
291(39.9) \\
32(4.4)\end{array}$ \\
\hline $\begin{array}{l}\text { TB treatment history } \\
\text { New } \\
\text { Previously treated* } \\
\text { Unknown }\end{array}$ & $\begin{array}{c}186(25.5) \\
511(70.0) \\
33(4.5)\end{array}$ \\
\hline $\begin{array}{l}\text { First RMP testing method } \\
\text { Phenotypic } \\
\text { LPA } \\
\text { Xpert }\end{array}$ & $\begin{array}{l}347(47.5) \\
199(27.3) \\
184(25.2)\end{array}$ \\
\hline $\begin{array}{l}\text { Treatment centre } \\
\text { Kabutare } \\
\text { Kibagabaga } \\
\text { Kibungo }\end{array}$ & $\begin{array}{c}563(82.7) \\
71(10.4) \\
47(6.9)\end{array}$ \\
\hline $\begin{array}{l}\text { MDR-TB treatment regimen } \\
\text { Long duration } \\
\text { Short course } \\
\text { Not treated }^{\dagger}\end{array}$ & $\begin{array}{c}510(69.9) \\
171(23.4) \\
49(6.7)\end{array}$ \\
\hline $\begin{array}{l}\text { Treatment outcome } \\
\text { Cured } \\
\text { Completed } \\
\text { Death during treatment } \\
\text { Death before treatment }\end{array}$ & $\begin{array}{c}457(62.6) \\
161(22.1) \\
63(8.6) \\
49(6.7)\end{array}$ \\
\hline
\end{tabular}

* Previously treated patients includes WHO Category 1 failure $(n=158$, $30.9 \%)$, Category 2 failure $(n=262,51.3 \%)$, Category 1 clinical relapse $(n=$ $51,10 \%)$, Category 2 clinical relapse $(n=21,4.1 \%)$, Category 1 defaulter $(n=$ $2,0.4 \%)$, Category 2 defaulter $(n=6,1.2 \%)$, MDR-TB treatment relapse $(n=$ $5,1 \%)$, MDR-TB treatment failure $(n=1,0.2 \%)$ and others $(n=5,1 \%)$.

${ }^{+}$Patients died before initiating treatment.

$\mathrm{RR}-\mathrm{TB}=$ rifampicin-resistant $\mathrm{TB} ; \mathrm{IQR}=$ interquartile range; HIV = human immunodeficiency virus; RMP = rifampicin; LPA = line-probe assay; MDR-TB = multidrug-resistant TB; $\mathrm{WHO}=$ World Health Organization .

IQR 9-53) compared to LPA (median 8 days, IQR 513) and five times longer compared to Xpert (median 4 days, IQR 2-5) $(P<0.01)$ (Table 4).

The median diagnostic delay was significantly longer $(P<0.01)$ in patients who died (median 80 days, IQR 34-96) than in patients who survived throughout MDR-TB treatment (median 50 days, IQR 5-84); however, the difference between the two groups was not statistically significant $(P=0.96)$ (Table 4).

Female patients had slightly longer diagnostic (median 67 days, IQR 11-86) and therapeutic (median 9 days, IQR 5-23) delays than males (median diagnostic delay 50 days, IQR 3-85 days; median therapeutic delay 7 days, IQR 4-18), although this was not statistically significant $(P=$ 0.09 for diagnostic, and $P=0.07$ for therapeutic delay) (Table 4).

Diagnostic and therapeutic delays were significantly shorter among patients aged $>54$ years: respectively 3 and 2 times shorter among those aged $<30$ years. Diagnostic delay was shorter $(P=0.01)$ in HIV co-infected patients (median 44 days, IQR 4-83) than in HIV-negative patients (median 66 days, IQR 8$86)$, although the difference was not statistically significant $(P=0.33)$ (Table 4$)$.

\section{Patient treatment outcome and factors associated with death}

Of the 730 patients included in the overall mortality analysis, $49(6.7 \%)$ died before starting MDR-TB treatment, while $63(8.6 \%)$ died during treatment (Table 3). Treatment was successful in 618 patients (84.7\%, 95\% confidence interval [CI] 81.8-87.2), $457(62.6 \%)$ of whom were declared cured and 161 $(22.1 \%)$ completed MDR-TB treatment.

Before 2009 when a long RR-TB diagnostic delay was the norm, mortality was significantly higher $(P<$ 0.01) in patients for whom MDR-TB treatment initiation had been based on available RMP DST results $(28.3 \%, 95 \% \mathrm{CI} 21.9-35.4)$ than in those who had been started on MDR-TB treatment before RRTB was confirmed $(8.9 \%, 95 \%$ CI 2.3-21.2).

RR-TB-related mortality decreased significantly from $30.8 \%(95 \%$ CI $19.9-43.4)$ in 2006 to $6.9 \%$ (95\% CI 2.3-15.5) in 2016 (Figure 4). In a multivariable analysis, total delay of at least 100 days was independently associated with mortality (adjusted odds ratio [aOR] 2.45, 95\% CI 1.35-4.46) (Table 5). After including patients who failed treatment and those lost to follow-up as dead, and those with unknown status of HIV under the HIV-coinfected category, and excluding all RR-TB diagnosed with very low bacillary load (Mycobacterium tuberculosis, $n=31$ ) using Xpert in sensitivity analyses, a total delay of at least 100 days was still significantly associated with mortality (respectively aOR 2.82, 95\% CI 1.60-4.97), aOR 3.71 (95\%CI 2.09-6.58) and aOR 2.38 (95\% CI 1.31-4.34) (Table 6).

HIV co-infection (aOR 2.27, 95\% CI 1.35-3.82) and age ( $>54$ years; aOR 4.83, 95\% CI 2.10-11.10) remained associated with increased mortality (Table 5). Other variables such as sex, MDR-TB treatment clinic and MDR-TB treatment regimen were not significantly associated with mortality (Table 5). Figure 5 shows that patients with a shorter diagnostic delay and those who were HIV-negative were more likely to survive $(P<0.001$ and $P=0.01$, respectively). 


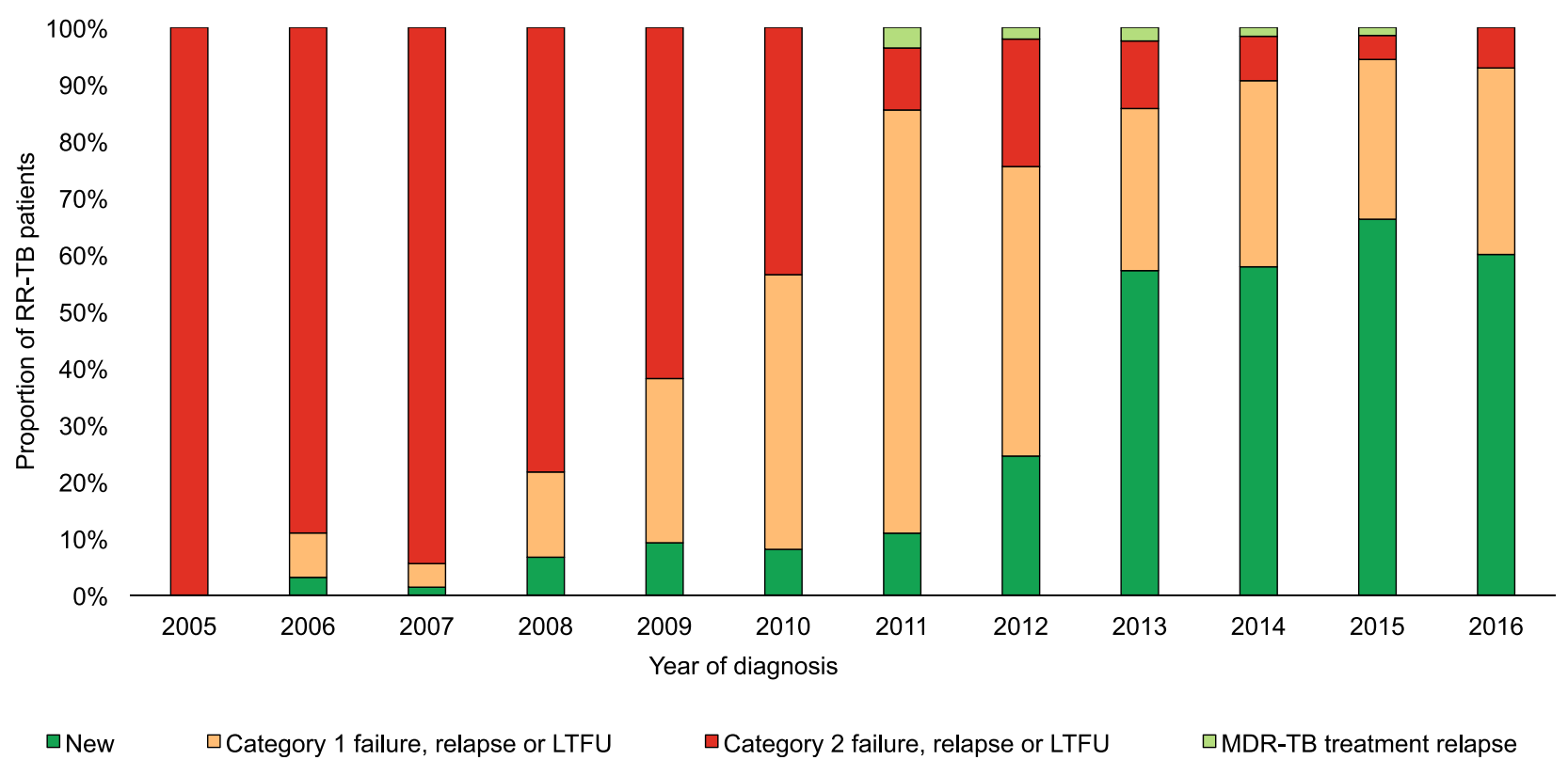

Figure 2 Proportion of patients with RR-TB based on their history of TB treatment by year of diagnosis. RR-TB =rifampicin-resistant tuberculosis; MDR-TB = multidrug-resistant TB.

\section{DISCUSSION}

To the best of our knowledge, this is the first nationwide RR-TB population-based study to show that a shortened diagnostic delay is associated with a decline in mortality. In Rwanda, RR-TB mortality dropped from $30.8 \%$ in 2006 to $6.9 \%$ in 2016 . Mortality was more than two-fold higher in patients with a total delay of $\geq 100$ days than in those with a delay of $<35$ days. Delays in diagnosing and treating RR-TB have been reduced through the nationwide scale-up of rapid molecular RMP DST since 2014 (Table 1), when $100 \%$ of RR-TB patients were diagnosed using molecular diagnostics, either Xpert $(81.3 \%)$ or LPA $(18.7 \%)$.

Our study showed that MDR/RR-TB mortality decreased as delays were reduced, mainly due to the implementation of Xpert. This findings contrasts with some previous studies which did not show an effect of the use of Xpert on TB mortality. ${ }^{18,19}$ On the other hand, our findings complement those from a Peruvian study conducted in patients already started

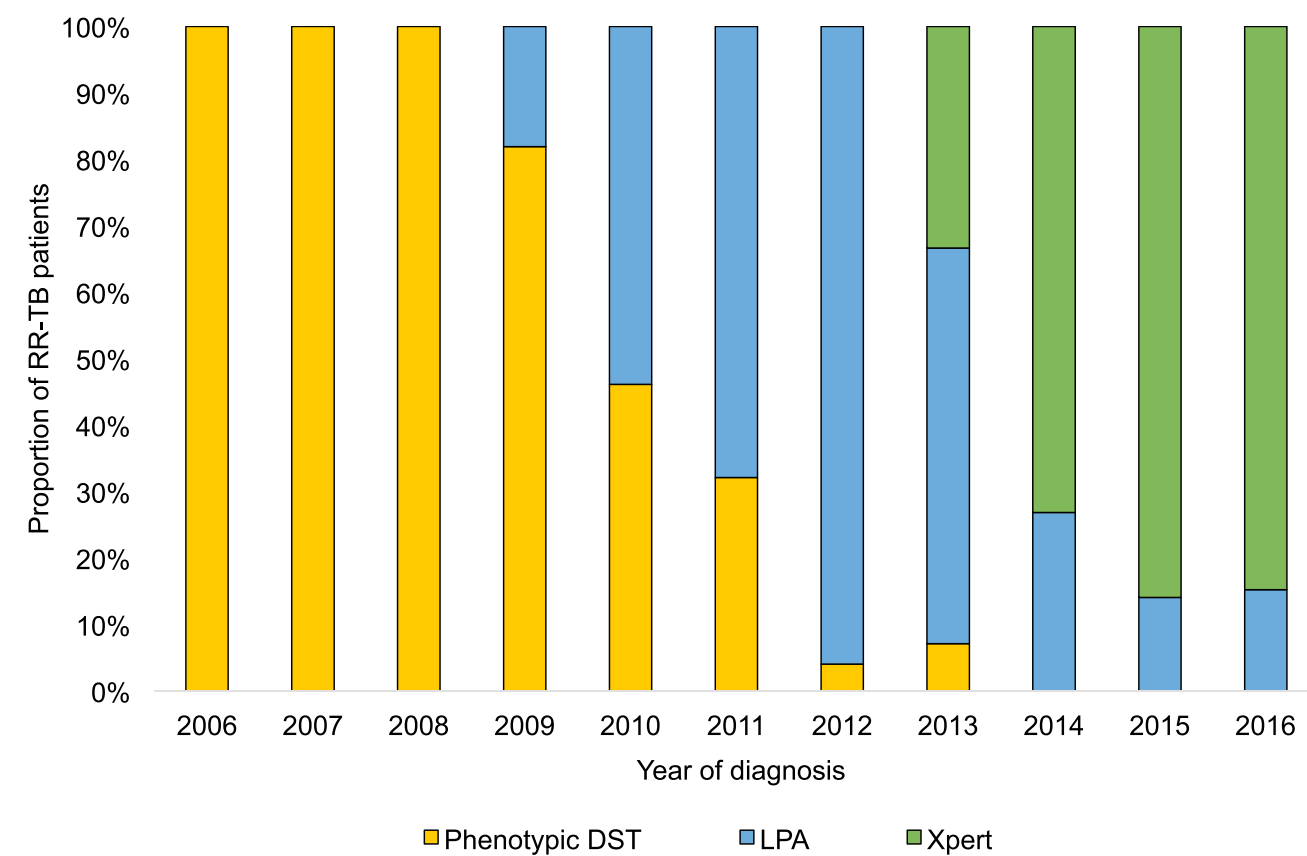

Figure 3 Diagnosis of RR-TB by type of RR-TB DST and year of diagnosis among patients with confirmed RR-TB $(n=611)$ before MDR-TB initiation. RR-TB = rifampicin-resistant tuberculosis; DST = drug susceptibility test; LPA = line-probe assay. 
Table 4 RR-TB diagnostic and treatment delay

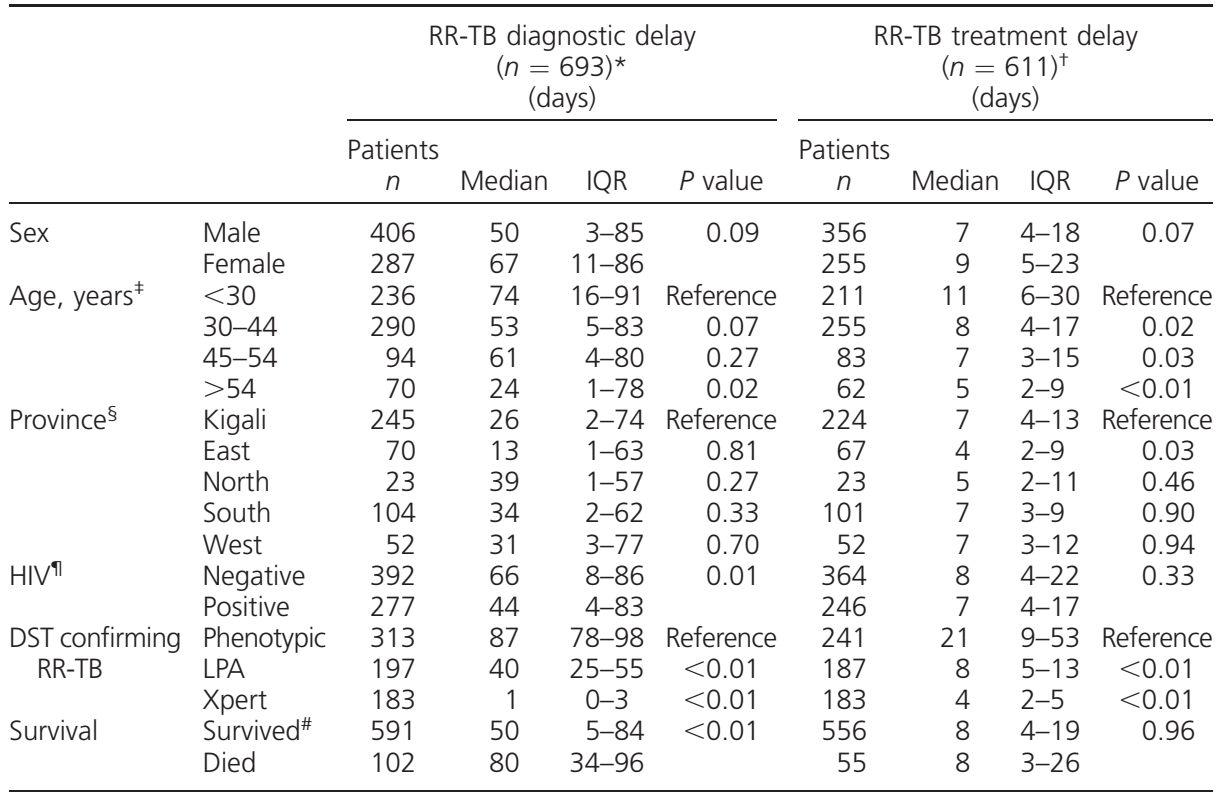

* Days between sample collection and rifampicin DST result available at RR-TB testing laboratory.

${ }^{\dagger}$ Days between rifampicin resistance diagnosis available at RR-TB testing laboratory and start of RR-TB appropriate treatment.

₹Patients without age information were not categorised.

$\S$ Patients diagnosed and initiated on MDR-TB treatment since 2009 onward.

" Patients with unknown HIV coinfection status were not included.

\#Patients who were reported as cured and those completed treatment.

$\mathrm{RR}-\mathrm{TB}=$ rifampicin-resistant TB; IQR = interquartile range; HIV = human immunodeficiency virus; $\mathrm{DST}=$ drug susceptibility testing; $\mathrm{LPA}=$ line-probe assay; $\mathrm{MDR}-\mathrm{TB}=$ multidrug-resistant TB

on MDR-TB treatment, which showed a decreased odds (0.5) of death and increased odds (1.4) of treatment success associated with the implementation of rapid phenotypic (microscopic-observation drug susceptibility) and genotypic (LPA) DST. ${ }^{13}$
Consistent with findings from other studies, ${ }^{13} \mathrm{HIV}$ coinfection and older age were associated with mortality, although HIV-coinfected and older patients were diagnosed more rapidly than HIVnegative and younger patients.

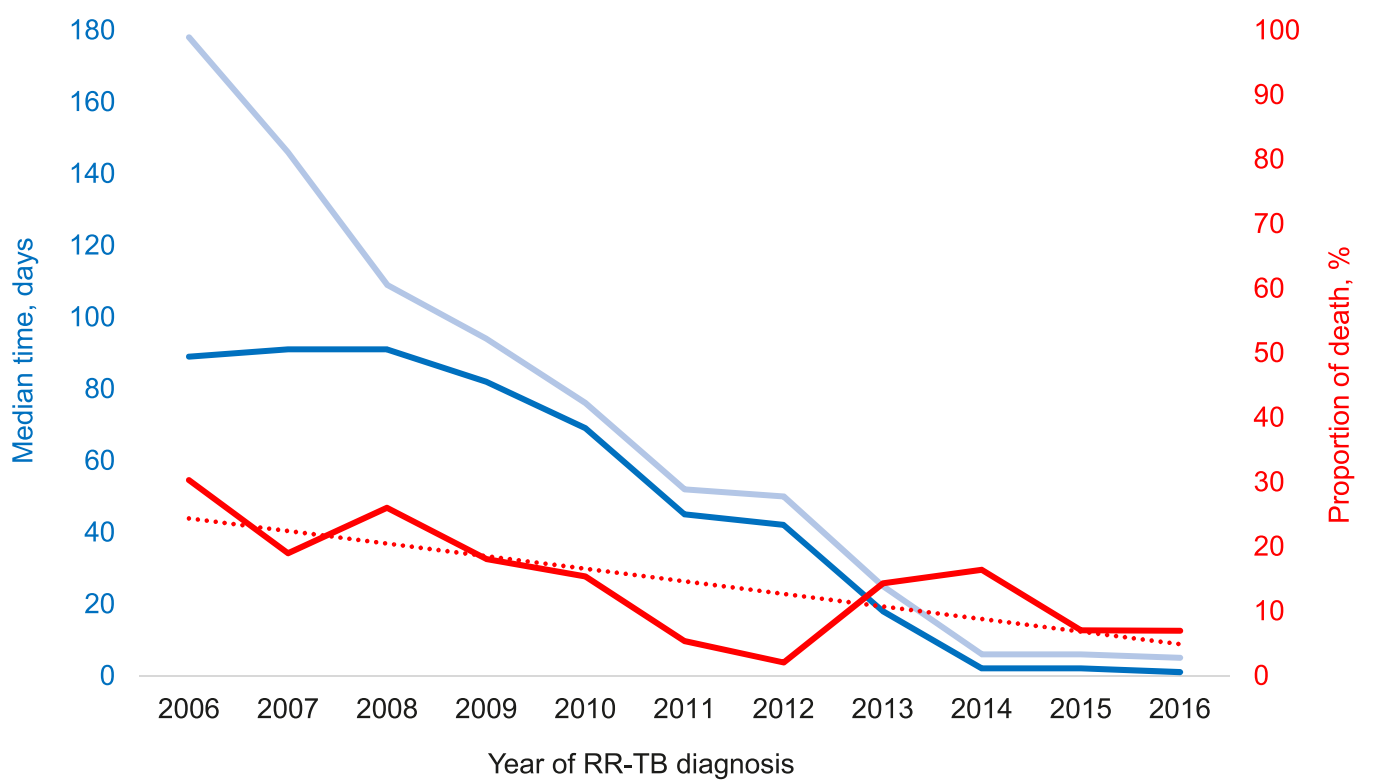

RR-TB diagnostic delay
Mortality

Total delay in initiating MDR-TB treatment ...... Linear (mortality)

Figure 4 RR-TB diagnostic delay and total delay in initiating MDR-TB (time in days between the date of sample collection that led to diagnosis of rifampicin resistance and date of MDR-TB treatment initiation) and mortality recorded by year of diagnosis. RR-TB $=$ rifampicin-resistant tuberculosis; MDR-TB = multidrug-resistant TB. 
Table 5 Factors associated with RR-TB mortality

\begin{tabular}{|c|c|c|c|c|}
\hline & $\begin{array}{c}\text { Total } \\
n\end{array}$ & $\begin{array}{l}\text { Death* } \\
n(\%)\end{array}$ & $\begin{array}{c}\text { Univariate analyses } \\
\text { OR }(95 \% \mathrm{Cl})\end{array}$ & $\begin{array}{c}\text { Multivariable analyses } \\
\text { aOR }(95 \% \mathrm{Cl})^{\dagger}\end{array}$ \\
\hline Total & 730 & $112(15.3)$ & & \\
\hline \multicolumn{5}{|l|}{ Sex } \\
\hline Female & 310 & $41(13.2)$ & $\begin{array}{l}\text { Reference } \\
\text { (2) }\end{array}$ & Reference \\
\hline Male & 420 & $71(16.9)$ & $1.33(0.88-2.02)$ & $1.57(0.93-2.62)$ \\
\hline \multicolumn{5}{|l|}{ Age, years } \\
\hline$<30$ & 252 & $22(8.7)$ & Reference & Reference \\
\hline $30-44$ & 311 & $59(19.0)$ & $2.45(1.45-4.12)$ & $2.11(1.08-4.12)$ \\
\hline $45-54$ & 96 & $15(15.6)$ & $1.94(0.96-3.91)$ & $2.20(0.95-5.08)$ \\
\hline$>54$ & 71 & $16(22.5)$ & $3.04(1.50-6.17)$ & $4.83(2.10-11.10)$ \\
\hline \multicolumn{5}{|l|}{ HIV } \\
\hline Negative & 407 & $34(8.4)$ & Reference & Reference \\
\hline Positive & 291 & $47(16.2)$ & $2.11(1.32-3.38)$ & $2.27(1.35-3.82)$ \\
\hline Unknown & 32 & 31 (96.9) & & \\
\hline \multicolumn{5}{|c|}{ RR-TB total delay, days ${ }^{\ddagger}$} \\
\hline $1-34$ & 232 & $23(9.9)$ & Reference & Reference \\
\hline $35-99$ & 235 & $29(12.3)$ & $1.28(0.72-2.28)$ & $1.28(0.68-2.44)$ \\
\hline At least 100 & 226 & $50(22.1)$ & $2.58(1.51-4.40)$ & $2.45(1.35-4.46)$ \\
\hline Unknown & 37 & $10(27.0)$ & & \\
\hline \multicolumn{5}{|c|}{ MDR-TB treatment clinics } \\
\hline Kibagabaga & 71 & $5(7.0)$ & Reference & \\
\hline Kibungo & 47 & $4(8.5)$ & $1.23(0.31-4.83)$ & \\
\hline Kabutare & 563 & 54 (9.6) & $1.40(0.31-4.83)$ & \\
\hline Not treated & 49 & $49(100)$ & & \\
\hline \multicolumn{5}{|c|}{ MDR-TB treatment regimen } \\
\hline Short course & 510 & $14(8.2)$ & Reference & \\
\hline Long duration & 171 & 49 (9.6) & $1.19(0.64-2.22)$ & \\
\hline Not treated & 49 & 49 (100) & & \\
\hline
\end{tabular}

* A total number of 112 persons died. Data were missing for some explanatory variables: total delay was missing for 37 patients, age was missing for 4 patients (imputed median age was used), HIV status was not known for 31 patients and for 49 no MDR-TB treatment regimen and clinic was assigned, as they died before starting treatment. For patients missing therapeutic delay, imputed values based on patients' age, sex, HIV coinfection and diagnostic delay were used. ${ }^{\dagger}$ Adjusted for age, sex and HIV co-infection.

₹ Sum of time (in days) between sample collection and rifampicin susceptibility test result availability at testing laboratory and time (in days) between rifampicin resistance diagnosis availability at testing laboratory and start of appropriate RR-TB treatment.

$\mathrm{RR}-\mathrm{TB}=$ rifampicin-resistant tuberculosis; $\mathrm{OR}=$ odd ratio; $\mathrm{Cl}=$ confidence interval; $\mathrm{aOR}=$ adjusted $\mathrm{OR} ; \mathrm{HIV}=$ human immunodeficiency virus; MDR-TB = multidrug-resistant TB.

Although the clinical decision to start MDR-TB treatment before laboratory confirmation is challenging, it resulted in a lower mortality during the period that rapid molecular DST was not available and when diagnostic delays were very long. ${ }^{7}$ This should not be surprising. In patients with multiple risk factors, a susceptible RMP DST result is unlikely to lower the post-test probability below the treatment threshold, the minimal level of probability of having RR-TB that is required to start MDR-TB treatment. ${ }^{20}$ Hence, empirical RR-TB treatment seems justified in such situations, especially when an effective treatment is available and when delay is associated with mortality. ${ }^{21}$

In our study, the treatment success rate was relatively high $(84.7 \%) .{ }^{13}$ The high rate of treatment success is in line with low rates of resistance to second-line drugs such as fluoroquinolones ${ }^{22,23}$ and second-line injectables. None of the over 400 RR-TB

Table 6 Sensitivity analysis for factors associated with RR-TB mortality

\begin{tabular}{lccc}
\hline Total RR-TB delay, days & aOR $(95 \% \mathrm{Cl})^{*}$ & aOR $(95 \% \mathrm{Cl})^{\dagger}$ & aOR $(95 \% \mathrm{Cl})^{\ddagger}$ \\
\hline $1-34$ & Reference & Reference & Reference \\
$35-99$ & $1.31(0.71-2.40)$ & $1.73(0.93-3.18)$ & $1.13(0.58-2.18)$ \\
At least 100 & $2.82(1.60-4.97)$ & $3.71(2.09-6.58)$ & $2.38(1.31-4.34)$ \\
\hline
\end{tabular}

$\S$ Sum of days between sample collection and RR-TB DST result available at testing laboratory and days between rifampicin resistance diagnosis available at testing laboratory and start of RR-TB appropriate treatment.

* Considering patients who failed treatment and those lost to follow-up as dead, adjusted for age, sex and HIV cOinfection when lost to follow-up and failure on MDR-TB treatment were considered dead.

${ }^{\dagger}$ Considering those with unknown status of HIV as HIV-coinfected, adjusted for age, sex and HIV co-infection when patients with unknown HIV coinfection status are considered as HIV-positive.

${ }^{*}$ Excluding all RR-TB identified diagnosed on Xpert with very low bacillary load (very low M. tuberculosis, $n=31$ ) adjusted for age, sex and HIV co-infection excluding patients diagnosed on Xpert with TB very low (high likelihood of being false RR-TB).

$\mathrm{RR}-\mathrm{TB}=$ rifampicin-resistant $\mathrm{TB} ; \mathrm{aOR}=$ adjusted odd ratio; $\mathrm{Cl}=$ confidence interval; $\mathrm{HIV}$ = human immunodeficiency virus; $M D R-T B=$ multidrug-resistant TB 

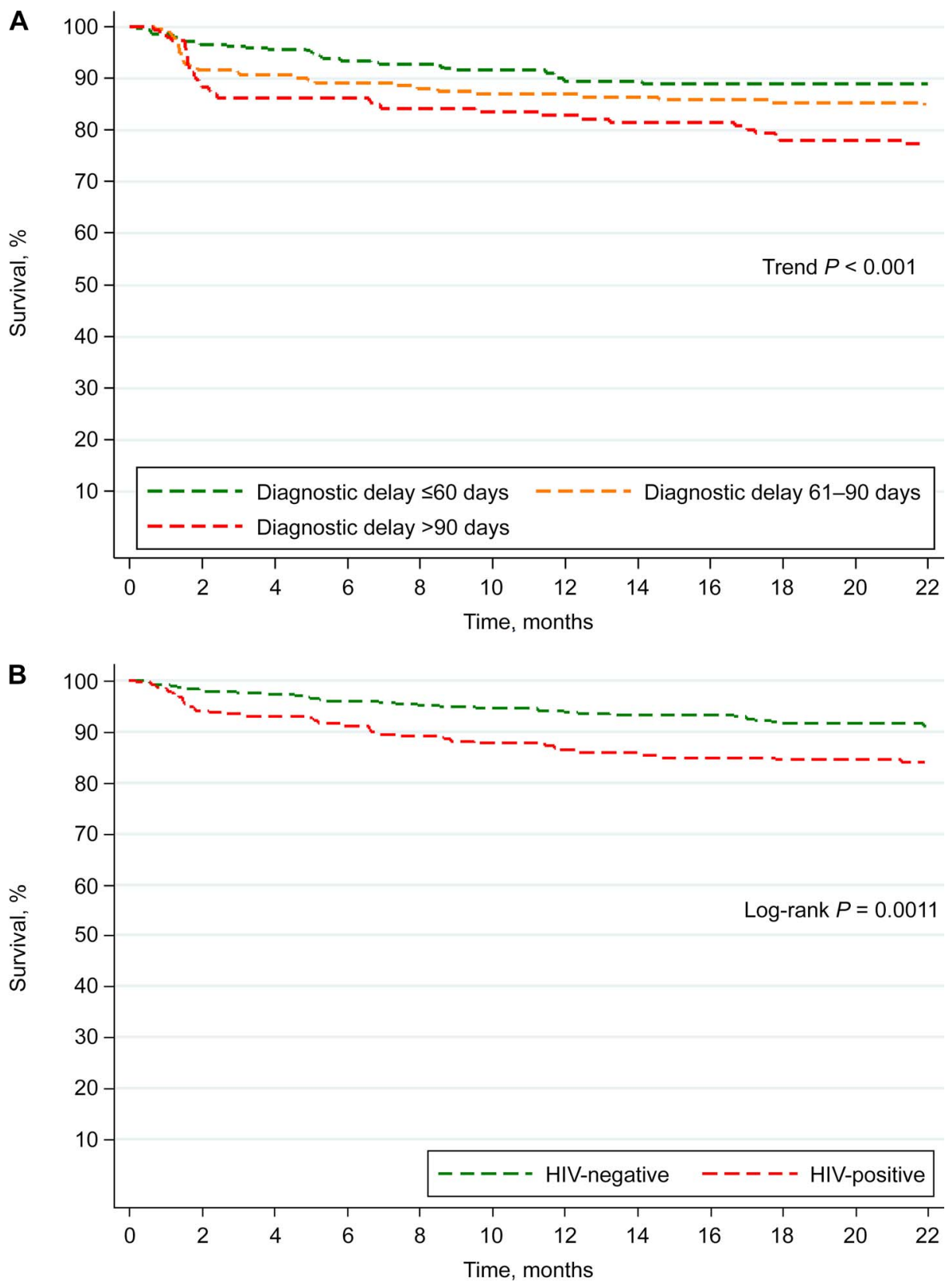

Figure 5 Kaplan-Meier survival estimates in patients with rifampicin-resistant tuberculosis by $\mathbf{A}$ ) diagnostic delay, and B) HIV coinfection. HIV = human immunodeficiency virus.

patients routinely tested since 2010 displayed resistance to these drugs (NRL Rwanda, unpublished findings), confirming that the standardised MDR-TB treatment used was effective in curing RR-TB and halting its spread. In fact, before the implementation of PMDT in Rwanda, the estimated prevalence of RR-TB among new TB patients rose from $1.3 \%$ (95\% CI $0.7-2.1)$ in 1993 to $3.9 \%$ (95\% CI $2.5-5.7)$ in 2005, 24,25 likely fuelled by ongoing transmission. ${ }^{26}$ Before RR-TB testing became easily accessible, the majority of the RR-TB patients diagnosed before 2013 had a primary RR-TB strain, but received multiple rounds of ineffective RMP-based treatment, while spreading RR-TB in their communities. This probably explains the increase of RR-TB prevalence among new TB patients, as shown in 2005. ${ }^{25}$ Since the implementation of PMDT, drug resistance surveys revealed a statistically significant decline in RR-TB prevalence among new TB patients, from 3.9\% (95\% CI $2.5-5.7)$ in 2005 to $1.4 \%(95 \%$ CI $0.7-2.1)$ in 2015..$^{25,27}$ Thus, the combination of early RR-TB diagnosis with effective MDR-TB treatment likely reduced transmission and probably explains the decrease in RR-TB prevalence, as observed in the 2015 survey. ${ }^{27}$

Nonetheless, the programme should be cautious of sole dependence on rapid molecular testing because 1) a shortage of reagents (e.g., cartridges) could 
completely paralyse the diagnostic system, ${ }^{28,29}$ 2) the increased sensitivity of the newly developed Xpert ${ }^{\circledR}$ MTB/RIF Ultra (Cepheid) may complicate its use in detecting true treatment failures or relapses, as persistent DNA may not reflect active disease, ${ }^{30} 3$ ) commercial rapid molecular diagnostics miss RMP resistance-conferring mutations outside the 81 base pair RMP resistance-determining region (RRDR), such as Val170Phe and Ile491Phe, ${ }^{31,32}$ and 4) falsepositive RR-TB results on Xpert may be associated with low bacillary load in the sample. ${ }^{33}$ However, a sensitivity analysis which excluded all RR-TB identified using Xpert with very low bacillary load did not affect the interpretation of the final model.

Our study had several important strengths. First, $85.4 \%$ of all patients diagnosed with RR-TB in Rwanda over a period of more than 10 years were included in the study. Our findings thus represent the current reality of the MDR/RR-TB programme in Rwanda. Second, in contrast with most studies on RR-TB outcomes, data from patients who died before starting treatment were included. Survival bias was therefore limited. Third, we validated data by comparing data collected from different sources (patient files, the national MDR-TB register and NRL registers). When discrepancies were identified, sources were consulted a second time. Finally, a sensitivity analysis including those who failed treatment or were lost to follow-up, was used to confirm the findings of the primary analysis.

Our study also had some important limitations. We did not collect data on the delay between the day a patient became at risk for MDR-/RR-TB and the date RMP DST was requested. In addition, we did not collect data on the severity of $\mathrm{TB}$ disease, such as extensiveness of TB on X-ray, the bacterial load in diagnostics or patient body mass index. Moreover, second-line drug susceptibility was not tested systematically and could not be taken into account. However, it should be noted that resistance to second-line drugs is extremely rare in Rwanda. Another important limitation was the lack of systematic data on timing of antiretroviral therapy initiation. The strong association between HIVcoinfection and RR-TB mortality could thus not be explored further. Finally, as this was a retrospective study, we could only adjust for those variables that were routinely collected.

In conclusion, diagnostic and treatment delays were strongly associated with RR-TB mortality in Rwanda. As the NTP were able to control delays, mortality declined from $30.8 \%$ in 2006 to $6.9 \%$ in 2016. Other factors that likely contributed to improved MDR-/RR-TB outcomes were universal RMP resistance surveillance enhanced by performance-based financing and the implementation of effective standardised MDR-TB treatment. We anticipate that universal testing of all TB patients for RR-
$\mathrm{TB}$, short diagnostic and therapeutic delays, and effective MDR-TB treatment will further reduce RRTB prevalence in Rwanda.

\section{Acknowledgements}

The authors thank all staff members of the Mycobacteriology Section at the National Reference Laboratory and Tuberculosis and Other Respiratory Diseases Divisions of the Kibagabaga and Kabutare Hospitals; staff of MDR-TB clinics at Kibagabaga and Kabutare Hospitals for their contribution to data collection; the Ministry of Health and Rwanda Biomedical Centre (Kigali, Rwanda) management for facilitation; and the Belgian Directorate General for Development (Brussels, Belgium) for funding this work through a PhD fellowship to JCSN.

Disclaimer: JMS is currently a staff member of the World Health Organization; the author alone is responsible for the views expressed in this publication and these do not necessarily represent the decisions, policy or views of the WHO.

Conflicts of interest: none declared.

\section{References}

1 Manson A L, Cohen K A, Abeel T, et al. Genomic analysis of globally diverse Mycobacterium tuberculosis strains provides insights into the emergence and spread of multidrug resistance. Nature Genet 2017; 49(3): 395-402.

2 van Cutsem G, Isaakidis P, Farley J, Nardell E, Volchenkov G, Cox H. Infection control for drug-resistant tuberculosis: early diagnosis and treatment is the key. Clin Infect Dis 2016; 62 (Suppl 3): S238-S243.

3 World Health Organization. Global tuberculosis report, 2018. WHO/CDS/TB/2018.20. Geneva, Switzerland: WHO, 2018.

4 McBryde E S, Meehan M T, Doan T N, et al. The risk of global epidemic replacement with drug-resistant Mycobacterium tuberculosis strains. Int J Infect Dis 2017; 56: 14-20.

5 Boyd R, Ford N, Padgen P, Cox H. Time to treatment for rifampicin-resistant tuberculosis: systematic review and metaanalysis. Int J Tuberc Lung Dis 2017; 21(11): 1173-1180.

6 Fox G J, Schaaf H S, Mandalakas A, Chiappini E, Zumla A, Marais B J. Preventing the spread of multidrug-resistant tuberculosis and protecting contacts of infectious cases. Clin Microbiol Infect 2017; 23(3): 147-153.

7 Chen Y, Yuan Z, Shen X, Wu J, Wu Z, Xu B. Time to multidrugresistant tuberculosis treatment initiation in association with treatment outcomes in Shanghai, China. Antimicrob Agents Chemother 2018; 62(4): AAC.02259-17.

8 Nair D, Navneethapandian P D, Tripathy J P, et al. Impact of rapid molecular diagnostic tests on time to treatment initiation and outcomes in patients with multidrug-resistant tuberculosis, Tamil Nadu, India. Trans R Soc Trop Med Hyg 2016; 110(9): 534-541.

9 Zhang X, Yin J, Li H, et al. Diagnostic and treatment delays of multidrug-resistant tuberculosis before initiating treatment: a cross-sectional study. Trop Med Int Health 2015; 20(11): 14311437.

10 van Kampen S C, Susanto N H, Simon S, et al. Effects of introducing xpert $\mathrm{mtb} / \mathrm{rif}$ on diagnosis and treatment of drugresistant tuberculosis patients in Indonesia: a pre-post intervention study. PLoS One 2015; 10(6): e0123536.

11 Cox H, Hughes J, Daniels J, et al. Community-based treatment of drug-resistant tuberculosis in Khayelitsha, South Africa. Int J Tuberc Lung Dis 2014; 18(4): 441-448.

12 Iruedo J, O'mahony D, Mabunda S, Wright G, Cawe B. The effect of the Xpert MTB/RIF test on the time to MDR-TB treatment initiation in a rural setting: a cohort study in South Africa's Eastern Cape Province. BMC Infect Dis 2017; 17(1): 91. 
13 Obregón G, Zevallos K, Alarcón V, et al. Rapid drug susceptibility testing and treatment outcomes for multidrugresistant tuberculosis in Peru. Int J Tuberc Lung Dis 2018; 22(11): 1350-1357.

14 Harris R C, Grandjean L, Martin L J, et al. The effect of early versus late treatment initiation after diagnosis on the outcomes of patients treated for multidrug-resistant tuberculosis: a systematic review. BMC Infect Dis 2016; 16(1): 193.

15 Klinkenberg E. Epidemiological review and impact analysis of tuberculosis in Rwanda. The Hague, The Netherlands: KNBC, 2014. http://www.rbc.gov.rw/fileadmin/user_upload/rbc/ surveillance_system_tb_epidemiological_impact_assessment_ rwanda_2014.pdf Accessed January 2020.

16 Van Deun A, Maug A K J, Salim M A H, et al. Short, highly effective, and inexpensive standardized treatment of multidrugresistant tuberculosis. Am J Respir Crit Care Med 2010; 182(5): 684-692.

17 Trébucq A, Schwoebel V, Kashongwe Z, et al. Treatment outcome with a short multidrug-resistant tuberculosis regimen in nine African countries. Int J Tuberc Lung Dis 2018; 22(1): $17-25$.

18 McNerney R, Zumla A. Impact of the Xpert MTB/RIF diagnostic test for tuberculosis in countries with a high burden of disease. Curr Opin Pulm Med 2015; 21(3): 304-308.

19 Auld A F, Fielding K L, Gupta-Wright A, Lawn S D. Xpert MTB/RIF - why the lack of morbidity and mortality impact in intervention trials? Trans R Soc Trop Med Hyg 2016; 110(8): 432-444.

20 Pauker S G, Kassirer J P. Therapeutic decision making: a costbenefit analysis. N Engl J Med 1975; 293(5): 229-234.

21 Decroo T, Henríquez-Trujillo A R, De Weggheleire A, Lynen L. Rational use of Xpert testing in patients with presumptive $\mathrm{TB}$ : clinicians should be encouraged to use the test-treat threshold. BMC Infect Dis 2017; 17(1): 674.

22 Umubyeyi A, Rigouts L, Shamputa I C, Dediste A, Struelens M, Portaels F. Low levels of second-line drug resistance among multidrug-resistant Mycobacterium tuberculosis isolates from Rwanda. Int J Infect Dis 2008; 12(2): 152-156.

23 Umubyeyi A N, Rigouts L, Shamputa I C, Fissette K, Elkrim Y, de Rijk P W B, et al. Limited fluoroquinolone resistance among Mycobacterium tuberculosis isolates from Rwanda: results of a national survey. J Antimicrob Chemother 2007; 59(5): 10311033.

24 Carpels G, Fissette K, Limbana V, Van Deun A, Vandenbulcke W, Portaels F. Drug resistant tuberculosis in sub-Saharan Africa: an estimation of incidence and cost for the year 2000. Int J Tuberc Lung Dis 1995; 76(6): 480-486.

25 Umubyeyi A N, Vandebriel G, Gasana M, et al. Results of a national survey on drug resistance among pulmonary tuberculosis patients in Rwanda. Int J Tuberc Lung Dis 2007; 11(2): 189-194.

26 Ngabonziza J C S, Rigouts L, Mazarati J-B, et al. Transmission drives the increase of multidrug-resistant tuberculosis in Rwanda [presented abstract]. Int J Tuberc Lung Dis 2018; 22(11): 454.

27 World Health Organization. Global tuberculosis report, 2016. WHO/HTM/TB/2016.13. Geneva, Switzerland: WHO, 2016.

28 Rwanda Ministry of Health. Rwanda National Tuberculosis and Other Respiratory Communicable Diseases Annual Report. Kigali, Rwanda: MoH, 2018.

29 Ardizzoni E, Fajardo E, Saranchuk P, et al. Implementing the Xpert ${ }^{\circledR}$ MTB/RIF diagnostic test for tuberculosis and rifampicin resistance: outcomes and lessons learned in 18 countries. PLoS One 2015; 10(12): e0144656.

30 Kendall E A, Schumacher S G, Denkinger C M, Dowdy D W. Estimated clinical impact of the Xpert MTB/RIF Ultra cartridge for diagnosis of pulmonary tuberculosis: a modeling study. PLoS Med 2017; 14(12): e1002472.

31 Siu G K H, Zhang Y, Lau T C K, et al. Mutations outside the rifampicin resistance-determining region associated with rifampicin resistance in Mycobacterium tuberculosis. J Antimicrob Chemother 2011; 66(4): 730-733.

32 Zaw M T, Emran N A, Lin Z. Mutations inside rifampicinresistance determining region of rpoB gene associated with rifampicin-resistance in Mycobacterium tuberculosis. J Infect Public Health 2018; 11(5): 605-610.

33 Ocheretina O, Byrt E, Mabou M-M, et al. False-positive rifampin resistant results with Xpert MTB/RIF version 4 assay in clinical samples with a low bacterial load. Diagn Microbiol Infect Dis 2016; 85(1): 53-55.

34 Liu Z, Pan A, Wu B, et al. Feasibility of a new model for early detection of patients with multidrug-resistant tuberculosis in a developed setting of eastern China. Trop Med Int Health 2017; 22(10): 1328-1333. 
CONTEXTE: En 2005, en réponse à une prévalence croissante de la tuberculose résistante à la rifampicine (RR-TB) et aux résultats médiocres du traitement, le Rwanda a initié la gestion programmatique de la RR$\mathrm{TB}$, notamment l'expansion de l'accès systématique au test de pharmacosensibilité de la rifampicine et au traitement standardisé.

OBJECTIF: Décrire les tendances du retard au diagnostic et au traitement et estimer leur impact sur la mortalité de la RR-TB.

SCHÉMA: Une analyse rétrospective de données individuelles de $748(85,4 \%)$ patients sur 876 ayant eu un diagnostic de RR-TB déclarée à l'Organisation mondiale de la Santé entre le $1^{\text {er }}$ juillet 2005 et le 31 décembre 2016 au Rwanda. La régression logistique a été utilisée pour estimer l'impact du retard au diagnostic et au traitement sur la mortalité de la RR-TB.
RÉSULTATS : Entre 2006 et 2016, le délai médian du diagnostic a significativement diminué de 88 jours à 1 jour et le délai de traitement, de 76 jours à 3 jours. Parallèlement, la mortalité liée à la RR-TB a significativement diminué de $30,8 \%$ en 2006 à $6,9 \%$ en 2016. Un retard de traitement de la TB multirésistante (MDR-TB) de plus de 100 jours a été associé à un risque plus de deux fois supérieur de décès. Quand les délais ont été longs, la mise en œuvre d'un traitement empirique de la RR-TB a été associée à une diminution de la mortalité.

CONCLUSION : La diminution du retard au diagnostic et au traitement a réduit la mortalité de la RR-TB. Nous nous attendons à ce que le test systématique de RR-TB, un délai court de diagnostic et de traitement et un traitement standardisé efficace de la MDR-TB diminue encore la mortalité de la RR-TB.

RES U M E N

MARCO DEREFERENCIA: En el 2005, en respuesta a un aumento en la prevalencia de la tuberculosis resistente a rifampicina (RR-TB) y los desenlaces terapéuticos desfavorables, se inició en Rwanda el manejo programático de la RR-TB, que incluía la expansión del acceso a las pruebas sistemáticas de sensibilidad a rifampicina y al tratamiento normalizado.

O вJETIVO: Describir las tendencias del retraso en el diagnóstico y el tratamiento y analizar su efecto sobre la mortalidad por RR-TB.

MÉTODO: Se realizó un análisis retrospectivo de los datos individuales de 748 de los 876 pacientes $(85,4 \%)$ con diagnóstico de RR-TB notificados a la Organización Mundial de la Salud entre el $1^{\circ}$ de enero del 2005 y el 31 de diciembre del 2016 en Rwanda. Mediante regresión logística se calculó el efecto del retraso en el diagnóstico y el tratamiento sobre la mortalidad por RR-TB.

RESU LTA D O S: Del 2006 al 2016, la mediana del retraso diagnóstico disminuyó de manera considerable de 88 días a un día y la mediana del retraso terapéutico pasó de 76 a 3 días. De manera simultánea, se observó una importante disminución de la mortalidad por RR-TB, de $30,8 \%$ en el 2006 a $6,9 \%$ en el 2016 . Un retraso total del comienzo del tratamiento de la tuberculosis multirresistente (MDR-TB) superior a 100 días se asoció con una posibilidad de mortalidad superior al doble. Donde los retrasos eran prolongados, el comienzo empírico del tratamiento contra la RR-TB se asoció con una menor mortalidad.

CONCLUSIÓN: La disminución de los retrasos en el diagnóstico y el tratamiento disminuyó la mortalidad por RR-TB. Se propone que la realización de la prueba de resistencia a rifampicina a todos los pacientes, un corto lapso hasta el diagnóstico y el comienzo del tratamiento y un tratamiento eficaz normalizado de la MDR-TB disminuirán aún más la mortalidad por RRTB en Rwanda. 